\title{
Early rehospitalizations of frail elderly patients - the role of medications: a clinical, prospective, observational trial
}

This article was published in the following Dove Press journal:

Drug, Healthcare and Patient Safety

18 August 2017

Number of times this article has been viewed

\author{
Niklas Ekerstad ${ }^{1,2}$ \\ Kristoffer Bylin ${ }^{3}$ \\ Björn W Karlson ${ }^{3,4}$ \\ 'Department of Cardiology, NU \\ (NÄL-Uddevalla) Hospital Group, \\ Trollhättan, ${ }^{2}$ Department of Medical \\ and Health Sciences, Division of \\ Health Care Analysis, Linköping \\ University, Linköping, ${ }^{3}$ Department \\ of Acute and Internal Medicine, \\ NU (NÄL-Uddevalla) Hospital \\ Group, Trollhättan, ${ }^{4}$ Department of \\ Molecular and Clinical Medicine, \\ Institute of Medicine, Sahlgrenska \\ Academy, University of Gothenburg, \\ Gothenburg, Sweden
}

Background and objective: Early readmissions of frail elderly patients after an episode of hospital care are common and constitute a crucial patient safety outcome. Our purpose was to study the impact of medications on such early rehospitalizations.

Patients and methods: This is a clinical, prospective, observational study on rehospitalizations within 30 days after an acute hospital episode for frail patients over the age of 75 years. To identify adverse drug reactions (ADRs), underuse of evidence-based treatment and avoidability of rehospitalizations, the Naranjo score, the Hallas criteria and clinical judgment were used. Results: Of 390 evaluable patients, 96 (24.6\%) were rehospitalized. The most frequent symptoms and conditions were dyspnea $(n=25)$ and worsened general condition $(n=18)$. The most frequent diagnoses were heart failure $(n=17)$ and pneumonia/acute bronchitis $(n=13)$. By logistic regression analysis, independent risk predictors for rehospitalization were heart failure (odds ratio $[\mathrm{OR}]=1.8 ; 95 \% \mathrm{CI}=1.1-3.1)$ and anemia $(\mathrm{OR}=2.3 ; 95 \% \mathrm{CI}=1.3-4.0)$. The number of rehospitalizations due to probable ADRs was 13, of which two were assessed as avoidable. The number of rehospitalizations probably due to underuse of evidence-based drug treatment was 19 , all of which were assessed as avoidable. The number of rehospitalizations not due to ADRs or underuse of evidence-based drug treatment was 64 , of which none was assessed as avoidable. Conclusion: One out of four frail elderly patients discharged from hospital was rehospitalized within 1 month. Although ADRs constituted an important cause of rehospitalization, underuse of evidence-based drug treatment might be an even more frequent cause. Potentially avoidable rehospitalizations were more frequently associated with underuse of evidence-based drug treatment than with ADRs. Efforts to avoid ADRs in frail elderly patients must be balanced and combined with evidence-based drug therapy, which can benefit these patients.

Keywords: frail elderly, early rehospitalizations, causes, drugs, patient safety

\section{Introduction}

\section{Background}

Frailty is a biological syndrome, implying reduced physiological reserves and vulnerability to stressors. ${ }^{1,2}$ Frailty is highly associated with functional decline, activity limitations and prolonged recovery for the individual. It also predicts a high risk of being institutionalized and dying within a short time..$^{3-5}$ Frail elderly patients constitute a high percentage of individuals treated in specialized acute care units, and they are characterized by high use of health care resources. ${ }^{6,7}$

Early readmissions of frail elderly patients after an episode of hospital care are common $^{8,9}$ and constitute a crucial patient safety outcome and risk predictor. Early rehospitalization rates have been reported to be associated with age, comorbidity,
Correspondence: Niklas Ekerstad Department of Cardiology, NU (NAL-Uddevalla) Hospital Group, Larketorpsvägen, 46100 Trollhättan, Sweden

Tel +46736249652

Fax +46 104357129

Email niklas.ekerstad@vgregion.se 
length of hospital stay, polypharmacy, worsening of functional status, ${ }^{10}$ severe morbidities at discharge, preadmission activities of daily living (ADL), malignant disease, dementia, high educational level, ${ }^{11}$ frailty ${ }^{12}$ and discharge from hospital based on patient's own request. ${ }^{13}$ The most frequent diagnosis-related causes are cardiovascular disease and pulmonary disease. ${ }^{14}$ Several risk prediction models for hospital readmission have been described, ${ }^{15,16}$ and strategies to reduce readmissions have been outlined. ${ }^{17}$ In a systematic review, however, most such interventions were reported to have limited, if any, effect. ${ }^{18}$

Adverse drug reactions (ADRs) are defined as "any noxious, unintended, and undesired effect of a drug, excluding therapeutic failures, intentional and accidental poisoning, and drug abuse." ${ }^{19}$ Causality assessment scales have been widely used to determine the likelihood that an individual patient's condition indeed is an ADR, i.e., that a drug caused the undesirable condition. ${ }^{20,21}$ There are also sets of criteria to assess the avoidability of an identified ADR. ${ }^{22}$ Despite the presence of these scales, it can be very difficult to decide whether an adverse clinical event is really an ADR or due to worsening of the patient's disease. ${ }^{23,24}$

Of all hospital admissions in older patients, several studies have reported 6-12\% to be due to ADRs. ${ }^{23,25-27}$ However, in a recent large study, $3.3 \%$ of admissions of patients aged 65 years or older were reported to be ADR related, ${ }^{28}$ while in another study it was $18 \% .^{29}$ Some ADR-related hospitalizations are unavoidable, but a substantial proportion of hospital admissions for ADRs has been judged to be avoidable, ${ }^{29-31}$ including ADRs due to missed contraindications, improper dosage, foreseeable drug interactions or reexposure of patients who have known drug allergies or other medication errors. ${ }^{32}$ The main risk factors for ADR-related hospitalizations in older patients have been identified as advanced age, many drugs, multimorbidity and potentially inappropriate medications. $^{23,33}$

ADRs are more frequently identified in frail elderly patients than in younger patients, ${ }^{34,35}$ and they are more likely to cause hospitalizations. ${ }^{36}$ This is attributed to somatic age-related changes in the metabolism, i.e., the capacity of elimination of drugs, polypharmacy and morbidity implying an increased vulnerability in various organs. ADR risk also increases with a larger comorbidity burden, inappropriate prescribing and suboptimal monitoring of drugs. ${ }^{37}$ The drugs that most frequently are reported to have caused an ADR are cardiovascular drugs, drugs with central nervous effects, anticoagulants and nonsteroidal anti-inflammatory drugs (NSAIDs). The most common clinical manifestations are falls, orthostatic hypotension, bleeding, delirium and renal failure. ${ }^{37}$

It has been pointed out that polypharmacy might be appropriate in some clinical contexts. ${ }^{28,38}$ Most studies have focused on overuse, or inappropriate use of drug treatments. However, the opposite can also be of significant importance. In one study, $13 \%$ of hospital admissions were assessed to be medication related, and including also underuse of evidencebased regimens. ${ }^{39}$ Of these admissions, 20\% were classified as preventable. Underuse of drugs in an elderly care context has been reported, even when there is reasonable evidence for beneficial effects also for elders, e.g., regarding anticoagulants in atrial fibrillation, ${ }^{40,41}$ Angiotensin converting enzyme (ACE) inhibitors/ angiotensin II receptor blockers (ARBs) and beta-blockers in heart failure ${ }^{42,43}$ and anti-dementia drugs. ${ }^{44}$ Focusing on avoiding ADRs might lead to reductions in the potential benefits of drug therapy. ${ }^{45}$

\section{Importance}

Early rehospitalizations of frail elderly patients are common and constitute a problem for the individual patient as well as for the health care system from a socioeconomic perspective. Polypharmacy is common for these patients, and ADRs have been pointed out as an important cause of admissions. However, there are also data indicating that underuse of evidencebased drug treatments in the elderly might be common even when clearly indicated. From a patient safety perspective, it is important to give a balanced description of the causes of early readmissions of frail elderly patients, including the role of medications.

\section{Goals of the investigation}

Our aim was to study the causes of early rehospitalizations of frail elderly patients, particularly in the context of medications, including both over- and underuse of evidence-based treatments.

\section{Patients and methods Study design and setting}

This is a clinical, prospective, observational study. It was carried out at the NU County Hospital Group in the Västra Götaland region in Sweden between March 2013 and July 2015 within the study entitled "Is the treatment of frail elderly patients effective in an elderly care unit (TREEE)." The TREEE study was approved by the independent ethics committee at the Sahlgrenska University Hospital in Gothenburg, Sweden $(8883-12,20121212)$ and registered at the Swedish National Database of Research and Development; identifier 


\section{1 (http://www.researchweb.org/is/vgr/project/113021;}

November 4, 2012).

\section{Selection of participants}

The selection of participants and primary data collection has been previously described. ${ }^{46}$ In summary, a total of 419 patients were included, 408 of whom could be evaluated. Inclusion criteria were as follows: age $\geq 75$ years, screened as frail according to the validated FRail Elderly Support ResearcH (FRESH) group screening instrument ${ }^{47}$ and assessed as being in need of inpatient care. Two or more of the following criteria in the FRESH screening instrument implied frailty: tiredness from a short walk, general fatigue, frequent falls/anticipation of falls, dependence in shopping and three or more visits to the emergency ward during the past 12 months. Exclusion criteria included patients in acute need of care at an organ-specific medical unit, e.g., patients with an acute myocardial infarction or a strong suspicion of stroke. During the index care episode, 18 out of the 408 patients died before discharge. Thus, 390 patients who were discharged alive could be studied regarding early rehospitalizations and their causes (Figure 1). All patients provided written informed consent to participate.

\section{Methods and measurements}

Clinical characteristics, hospital care consumption, rehospitalizations and mortality

The following data were collected from patients, medical records and registers during the index care episode and at the 3-month follow-up visit: age, gender, housing, diabetes mellitus, renal function, heart failure, other comorbidities, number of inhospital care days, rehospitalizations and mortality. ADL independence/dependence was assessed by using the ADL staircase before discharge..$^{48}$ The patient's total burden of morbidity was measured by the Charlson Comorbidity Index. ${ }^{49}$ The degree of frailty was determined using the FRESH screening instrument. ${ }^{47}$ The risk of malnutrition was assessed by the Mini Nutritional Assessment - short form (MNA-SF). ${ }^{50}$ Polypharmacy was defined as 10 or more drugs in one patient.

\section{Classification and characteristics of early rehospitalizations}

Early rehospitalization was defined as occurring within 30 days from index hospitalization discharge. Classification of cause and characteristics of early rehospitalizations were made retrospectively from medical records by clinical

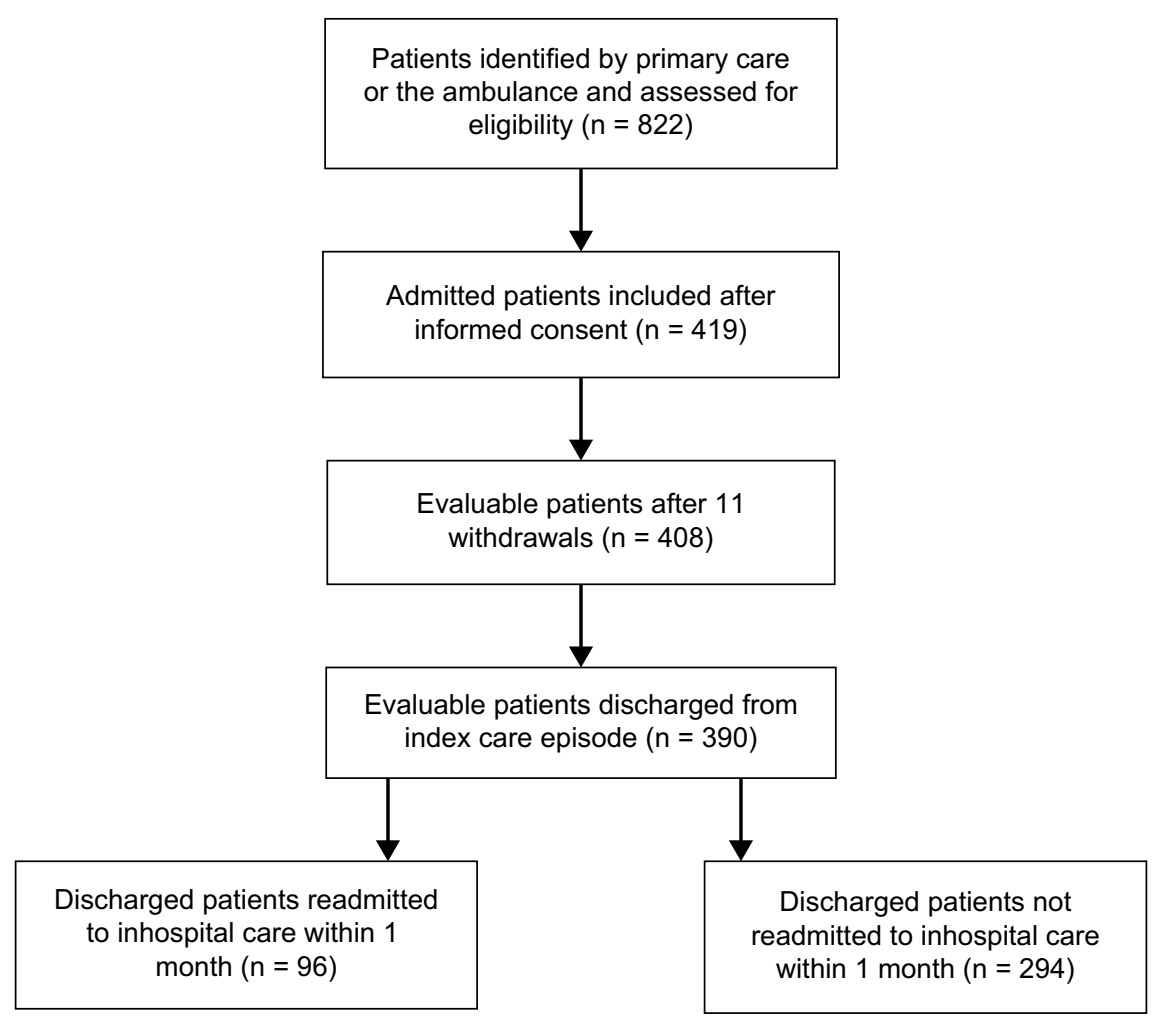

Figure I Flowchart of patients with a history of rehospitalizations. 
judgment and through scoring scales. Two senior clinicians independently classified the early rehospitalization cases into one of three categories based on the most probable main cause: 1) probably due to ADR according to clinical judgment and/or Naranjo scoring; 2) probably due to underuse of evidence-based drug treatment according to clinical judgment; and 3) probably not due to ADRs or underuse of evidence-based drug treatment. When the clinical judgment was discordant, a third clinician performed a final judgment.

The classification included the Naranjo score to identify an ADR as the cause of the condition. ${ }^{20,21} \mathrm{~A}$ condition was classified as ADR if deemed probable or definite, i.e., if the Naranjo score was $>4$. Similarly probable avoidability of the rehospitalization was assessed by clinical judgment and, when an ADR was identified, the Hallas criteria. ${ }^{22}$ If the Hallas criteria pointed out the ADR to be definitely avoidable, it was deemed to be avoidable in our study.

Early rehospitalization was classified as due to underuse of drug treatment when the absence of evidence-based treatment constituted the probable cause of the rehospitalization, and the indication was known at discharge and there was no absolute or relative contraindication.

\section{Statistical analysis}

The data were computerized and analyzed using the SPSS Statistics for Windows, Version 22.0 (IBM Corporation, Armonk, NY, USA). Descriptive data are presented as mean, one SD and median (range). The Student's $t$-test was used to calculate the $95 \%$ CI of the mean. Categorical data were analyzed using Fisher's exact test or the $\chi^{2}$ test, and the continuous data were compared using Student's $t$-test. When there was a significant difference, the Bonferroni post hoc test was used. A $p$-value of $\leq 0.05$ was considered statistically significant. Regarding adjusted analysis of factors predicting early rehospitalizations, a logistic regression model was used.

\section{Results}

\section{Characteristics of study subjects}

Of 390 evaluable patients discharged from the index care episode, 96 patients $(24.6 \%)$ were rehospitalized within 30 days, while 294 patients were not (75.4\%). Baseline characteristics of both groups are presented in Table 1. In unadjusted analysis, the groups did not differ significantly in terms of age, gender, total morbidity burden, living in residential care, own living with home help services, marital status, ADL, MNA, frailty score, duration of index hospital stay and most of the studied

Table I Baseline (index care episode) clinical and demographic characteristics of early readmitted patients ( $n=96)$ and patients not readmitted early ( $n=294)$, unadjusted analysis

\begin{tabular}{|c|c|c|c|}
\hline Characteristics & Readmitted early $(n=96)$ & Not readmitted early $(n=294)$ & $p$-value \\
\hline Age, mean (years) (SD) & $85.7(5.1)$ & $85.7(5.5)$ & 0.960 \\
\hline Gender, male, $n(\%)$ & $47(49.0)$ & $122(4 \mid .5)$ & 0.236 \\
\hline Charlson score, mean (SD) & $6.8(1.8)$ & $6.8(1.9)$ & 0.984 \\
\hline ADL score, mean (SD) & $4.9(2.2)$ & $4.4(2.6)$ & 0.064 \\
\hline Frailty score, mean (SD) & $3.5(0.95)$ & $3.4(0.84)$ & 0.350 \\
\hline MNA, mean (SD) & $10.2(2.4)$ & $10.2(2.6)$ & 0.968 \\
\hline Residential care,* n (\%) & II (II.5) & $37(12.6)$ & 0.859 \\
\hline Own living with home help services, $n$ (\%) & $38(60.4)$ & $146(49.7)$ & 0.078 \\
\hline Married/living in partnership, $\mathrm{n}(\%)$ & $26(27.1)$ & $105(35.7)$ & 0.136 \\
\hline Ischemic heart disease, $\mathrm{n}(\%)$ & $26(27.0)$ & $91(31.0)$ & 0.523 \\
\hline Chronic heart failure, n (\%) & $48(50.0)$ & $106(36.1)$ & 0.017 \\
\hline COPD, n (\%) & $18(18.8)$ & $57(19.4)$ & 1.000 \\
\hline Tumor, n (\%) & $12(12.9)$ & $52(17.7)$ & 0.269 \\
\hline Dementia, n (\%) & $7(7.3)$ & $37(12.6)$ & 0.194 \\
\hline Anemia, $n(\%)$ & $64(66.7)$ & $138(46.9)$ & 0.001 \\
\hline Diabetes, n (\%) & $20(20.8)$ & $48(16.3)$ & 0.353 \\
\hline Renal function, GFR & 38.9 & 53.1 & 0.155 \\
\hline Index diagnosis: acute heart failure, $n(\%)$ & $37(38.5)$ & $85(28.9)$ & 0.077 \\
\hline Index diagnosis: bacterial infection, $\mathrm{n}(\%)$ & $46(47.9)$ & $129(43.9)$ & 0.555 \\
\hline Index diagnosis: myocardial infarction, $\mathrm{n}(\%)$ & $6(6.2)$ & $12(4.1)$ & 0.403 \\
\hline Reported cases with 10 or more drugs, $\mathrm{n}(\%)$ & $60(62.5)$ & $159(54.0)$ & $<0.001$ \\
\hline LOS index, days, mean, $\mathrm{n}(\mathrm{SD})$ & $10.5(7.8)$ & $10.0(6.0)$ & 0.552 \\
\hline
\end{tabular}

Note: *Living in care facilities.

Abbreviations: ADL, activities of daily living; COPD, chronic obstructive pulmonary disease; GFR, glomerular filtration rate; LOS, length of stay; MNA, Mini Nutritional Assessment. 
diagnoses (all $p>0.05$ ). These data also indicate that disabilities, i.e., dependence or difficulty carrying out personal or instrumental $\mathrm{ADL}$, were common among the participants in both groups. Both groups were heavily affected by diseases, particularly cardiovascular disease. The exceptions were that the early rehospitalized participants had a significantly higher baseline prevalence of chronic heart failure $(p=0.017)$, anemia $(p=0.001)$ and a higher prevalence of polypharmacy $(p$ $<0.001)$. By logistic regression analysis, independent predictors for early rehospitalization were anemia $(p=0.0031)$ and chronic heart failure $(p=0.024)$, and none of the other baseline variables $(p>0.05)$.

\section{Main results}

Admission characteristics of early rehospitalized patients are presented in Table 2. The symptoms and conditions which most frequently caused readmissions were dyspnea $(n=25)$, worsened general condition/tiredness $(n=18)$, pain $(n=15)$, suspected infection $(n=14)$ and vertigo/falling $(n=10)$. The admission route was the ambulance for all these patients

Table 2 Admission characteristics of early readmissions $(n=96)$

\begin{tabular}{ll}
\hline Characteristics & N \\
\hline Primary diagnosis at index hospitalization & \\
Pneumonia/exacerbation/acute bronchitis & 21 \\
Heart failure & 19 \\
Urinary tract infection & 11 \\
Other infectious disease & 9 \\
Pain & 5 \\
Arrhythmia & 5 \\
Acute coronary syndrome & 5 \\
Vertigo & 4 \\
Anemia & 4 \\
Others & 13 \\
Cause of readmission, condition & \\
Dyspnea & 25 \\
Worsened general condition/tiredness & 18 \\
Pain & 15 \\
Fever/infection & 14 \\
Vertigo/falling & 10 \\
Others & 14 \\
Primary diagnosis at early rehospitalization & \\
Heart failure & 17 \\
Pneumonia/exacerbation/acute bronchitis & 13 \\
Other infectious disease & 10 \\
Urinary tract infection & 8 \\
Stroke/TIA & 7 \\
Fracture & 7 \\
Arrhythmia & 3 \\
Myocardial infarction/angina pectoris & 3 \\
Pain & 3 \\
Bleeding/anemia & 3 \\
Others & \\
\hline
\end{tabular}

Abbreviation: TIA, transient ischemic attack. $(\mathrm{n}=96)$. The four most frequent primary diagnoses at the index care episode for these patients in need of rehospitalization were pneumonia/exacerbation of chronic obstructive pulmonary disease (COPD)/acute bronchitis $(n=21)$, heart failure $(n=19)$, urinary tract infection $(n=11)$ and other infectious disease $(n=9)$. The four most frequent primary diagnoses at the early rehospitalization episode were heart failure $(n=17)$, pneumonia/exacerbation of COPD/acute bronchitis $(n=13)$, other infectious disease $(n=10)$ and urinary tract infection $(\mathrm{n}=8)$.

Early rehospitalizations probably due to ADRs according to clinical judgment and/or Naranjo scoring $(n=13)$ are presented in Table 3. The number of ADRs according to clinical judgment was 13, and according to the Naranjo score was 9. The nine patients with ADRs according to the Naranjo score were included in the 13 clinical judgment patients. Of these early rehospitalizations probably due to an ADR, two were classified as probably avoidable by clinical assessment. The same two patients were classified as probably avoidable by the Hallas score. None of these 13 patients died.

Early rehospitalizations identified through clinical judgment as probably due to underuse of evidence-based drug treatment, i.e., despite known indication at the index care episode and without known contraindication $(\mathrm{n}=19)$, are presented in Table 4 . The most frequently identified indications, not treated with evidence-based drug treatment, were heart failure $(n=11)$ and atrial fibrillation $(n=3)$. Of these 19 early rehospitalizations probably due to underuse of evidence-based drug treatment, all were classified as probably avoidable by clinical assessment. None of these 19 patients died.

Early rehospitalizations identified through clinical judgment as probably not due to ADRs or underuse of evidencebased drug treatment $(n=64)$ are presented in Table S1. None of these rehospitalizations were assessed as probably avoidable. Of these patients, eight died during the rehospitalization.

Regarding the comparison of the proportions of patients rehospitalized due to underuse of evidence-based drug treatment (19/96) and patients rehospitalized due to ADRs (13/96), there was no statistically significant difference ( $p=0.333$ ). Regarding the comparison of the proportions of patients rehospitalized due to underuse of evidence-based drug treatment, assessed to be avoidable (19/96), and patients rehospitalized due to ADRs, assessed to be avoidable (2/96), there was a statistically significant difference $(p<0.0001)$.

\section{Discussion}

In this study, one out of four frail elderly patients was rehospitalized within 1 month after discharge from a hospitalization 


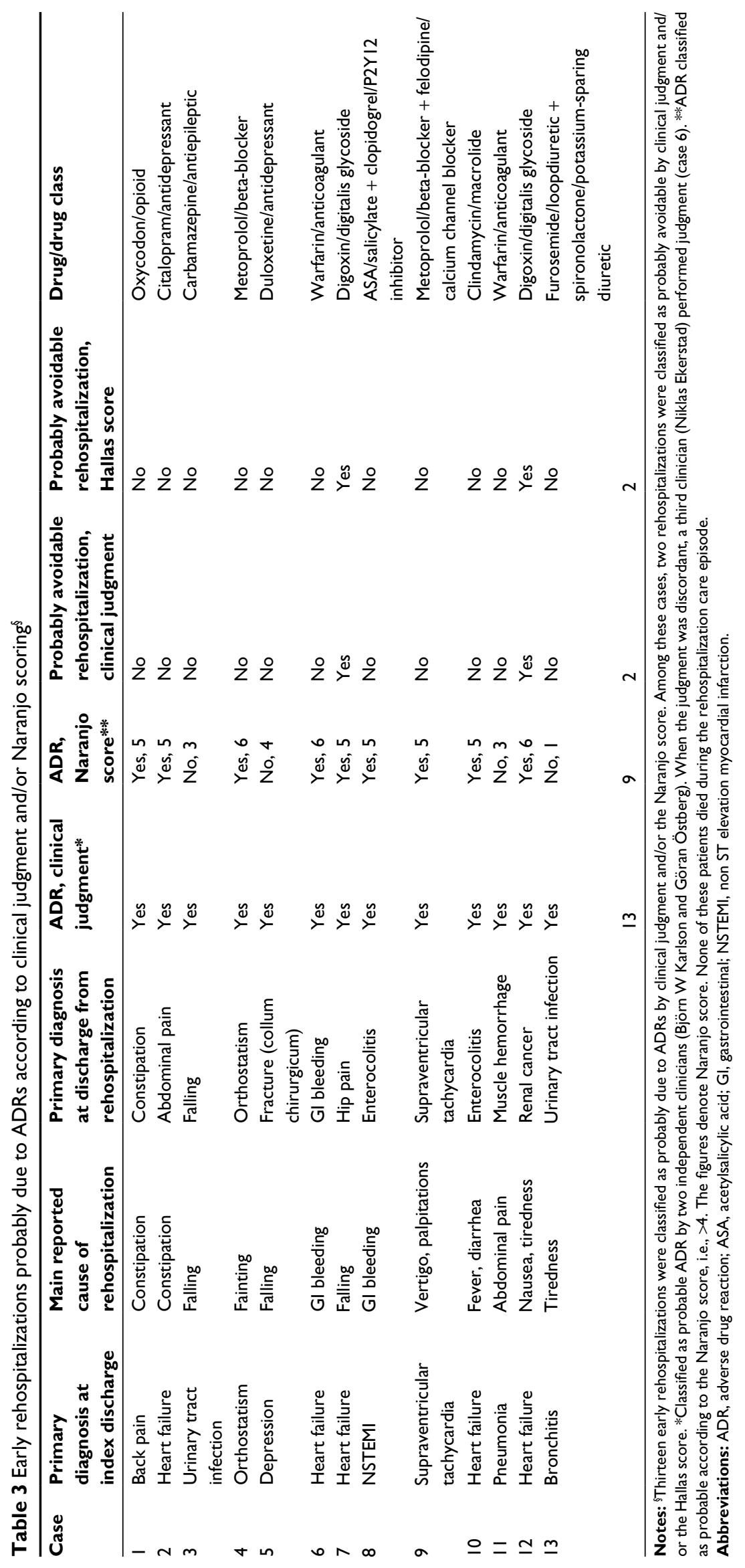


Table 4 Early rehospitalization probably due to drug underuse, according to clinical judgment ${ }^{\S}$

\begin{tabular}{|c|c|c|c|c|c|}
\hline Case & $\begin{array}{l}\text { Primary diagnosis } \\
\text { at index discharge }\end{array}$ & $\begin{array}{l}\text { Indication for drug } \\
\text { treatment known at } \\
\text { index care episode }\end{array}$ & $\begin{array}{l}\text { Absence of treatment at } \\
\text { discharge from index - } \\
\text { drug class* }\end{array}$ & $\begin{array}{l}\text { Main reported cause } \\
\text { of rehospitalization }\end{array}$ & $\begin{array}{l}\text { Primary diagnosis } \\
\text { at discharge from } \\
\text { rehospitalization }\end{array}$ \\
\hline I & Pneumonia & Pneumonia & Antibiotics & Dyspnea, cough & Pneumonia \\
\hline 2 & Heart failure & $\begin{array}{l}\text { Atrial fibrillation, } \\
\text { CHADS-VASC } 5\end{array}$ & Anticoagulant & Paresis & TIA \\
\hline 3 & Heart failure & Known previous stroke & ASA & Stroke & Cerebral infarction \\
\hline 4 & $\begin{array}{l}\text { COPD with } \\
\text { exacerbation }\end{array}$ & Heart failure & Beta-blocker & $\begin{array}{l}\text { Worsened general } \\
\text { condition }\end{array}$ & Worsened general condition \\
\hline 5 & Heart failure & Heart failure & ACE/ARB & Dyspnea & Heart failure \\
\hline 6 & $\begin{array}{l}\text { Urinary tract } \\
\text { infection }\end{array}$ & Heart failure & Beta-blocker & Dyspnea & Heart failure \\
\hline 7 & Unstable angina & Unstable angina & DAPT & Progressive chest pain & Chest pain \\
\hline 8 & $\begin{array}{l}\text { Abnormal ADH } \\
\text { sekretion }\end{array}$ & Heart failure & Beta-blocker & Dyspnea & Heart failure \\
\hline 9 & Malnutrition & Heart failure & ACE/ARB & Dyspnea, back pain & Heart failure \\
\hline 10 & Sick sinus syndrome & Heart failure & ACE/ARB & Dyspnea & Heart failure \\
\hline II & Pyelonefritis & Heart failure & ACE/ARB; beta-blocker & Tiredness & Worsened general condition \\
\hline 12 & $\begin{array}{l}\text { Enterocolitis } \\
\text { (C. difficile) }\end{array}$ & Enterocolitis (C. difficile) & Antibiotics & Diarrhea & Enterocolitis (C. difficile) \\
\hline 13 & Pneumonia & $\begin{array}{l}\text { Atrial fibrillation. } \\
\text { CHADS-VASC }\end{array}$ & Anticoagulants & Paresis, aphasia & Cerebral infarction \\
\hline 14 & Asthma & Heart failure & ACE/ARB & Dyspnea & Dyspnea \\
\hline 15 & Heart failure & Heart failure & Beta-blocker & Dyspnea & Heart failure \\
\hline 16 & COPD, exacerbation & Heart failure & ACE/ARB & Dyspnea & Heart failure \\
\hline 17 & Heart failure & Heart failure & Beta-blocker & Tiredness & Infection, heart failure \\
\hline 18 & COPD, exacerbation & COPD, exacerbation & Antibiotics & Dyspnea & COPD, exacerbation \\
\hline 19 & Diverticulitis & $\begin{array}{l}\text { Known paroxysmal atrial } \\
\text { fibrillation }\end{array}$ & Anticoagulants & Dysarthria & Stroke \\
\hline
\end{tabular}

Notes: §Early rehospitalization classified as probably due to underuse of evidence-based drug treatment despite known indication at discharge from the index care episode. Classified as probably avoidable rehospitalization by two independent clinicians (Niklas Ekerstad and Björn W Karlson). *Absence of evidence-based treatment constituting the probable cause of rehospitalization. Known indication and no known contraindication. Of these 19 early rehospitalizations probably due to underuse of evidence-based drug treatment, all were classified as probably avoidable by clinical assessment. None of these patients died during the rehospitalization care episode.

Abbreviations: ACE/ARB, angiotensin converting enzyme-inhibitor/angiotensin II receptor antagonist; ADH, antidiuretic hormone secretion; $A S A$, acetylsalicylic acid; $C$. difficile, Clostridium difficile; COPD, chronic obstructive pulmonary disease; DAPT, dual antiplatelet therapy; TIA, transient ischemic attack.

episode. The most frequently reported symptoms causing rehospitalization were dyspnea and tiredness, and the most frequently reported diagnoses were heart failure and infectious disease. Independent risk predictors for rehospitalization were heart failure and anemia at index hospitalization discharge.

ADRs were reported to be the main cause in 13 of the 96 $(13.5 \%)$ rehospitalizations when assessment was performed through clinical judgment, and in nine of the $96(9.4 \%)$ rehospitalizations when the Naranjo scale was used. In two of the $96(2.1 \%)$ rehospitalizations, avoidable ADRs were assessed to be the main cause, according to clinical judgment as well as according to the Hallas avoidability criteria. The drugs most frequently reported to have caused an ADR were warfarin, digoxin and antidepressants. The most common clinical manifestations were bleeding, gastrointestinal symptoms and falls.

Underuse of evidence-based drug treatment, i.e., no treatment at discharge despite the known presence of an indication and the absence of contraindication, was assessed through clinical retrospective judgment to be the main probable cause of rehospitalization in 19 of the $96(19.8 \%)$ patients. All of these undertreatment cases were assessed as potentially avoidable. The diagnoses most frequently associated with underuse of evidence-based drug treatment were heart failure and atrial fibrillation. The drugs that consequently most frequently were reported to be underused were ACE inhibitors/ARBs, beta-blockers and anticoagulants.

The rate of early rehospitalizations in this study is higher compared to most previous reports. ${ }^{8,9}$ This is most probably due to the characteristics of our study population including high age, multimorbidity and frailty, which are all considered to predict rehospitalizations.

ADRs constituted the probable main cause of readmission for $9.4-13.5 \%$ of the patients, which resembles the percentages reported in previous studies. ${ }^{23}$ Only two avoidable ADRs as main cause of readmission were identified, i.e., $15.4 \%(2 / 13)$ up to $22.2 \%(2 / 9)$ of all ADRs causing 
rehospitalizations. This proportion is lower than reported in some previous studies, ${ }^{30,31}$ although similar to the percentage avoidable ADRs reported in a recent study. ${ }^{29}$ Furthermore, extrapolating this proportion of rehospitalizations due to avoidable ADRs to a clinical population of frail elderly would imply that many patients are affected.

Underuse of evidence-based drug treatment was assessed to be the main probable cause in as much as $19.8 \%$ of rehospitalizations in our study, and all of these were assessed to be potentially avoidable. This was based on the presumption that the symptoms causing rehospitalizations, e.g., dyspnea from heart failure, might have been prevented or delayed by evidence-based drug therapy. This estimate might even be conservative, since in cases of a relative, rather than an absolute, contraindication we did not classify the rehospitalization as due to underuse of drug treatment. To our knowledge, very few trials have studied early rehospitalizations from this viewpoint. However, in one study, $13 \%$ of hospital admissions were assessed to be medication related including underuse of evidence-based regimens. Of these admissions, 20\% were classified as preventable. ${ }^{39}$

Evidence-based use of drugs has a definite potential to benefit also elderly patients, in some cases even more than in younger patients, since the disease-related risk usually is higher. Despite that the majority of publications focus on drug overuse in the elderly, there are also indications of underuse of drugs, even when there is reasonable evidence for beneficial effects also for elders, e.g., regarding atrial fibrillation (anticoagulants) and heart failure (ACE inhibitors/ARBs and beta-blockers). Powerful efforts to avoid all possible ADRs might switch the benefit-risk balance and lead to suboptimal use of evidence-based drug therapy. ${ }^{45}$

It is a strength that our study included very frail elderly patients with a heavy comorbidity burden, while these patients would be excluded in most clinical trials. Further, most previous trials studying rehospitalizations of elderly have focused on ADRs, while our aim to describe both ADRs and underuse of drugs, i.e., a balanced perspective, comes closer to the considerations and trade-offs which have to be made in the daily clinical work. Moreover, it is a strength that we combined clinical assessment of ADRs and underuse of drugs with the use of two of the most common assessment scales, including judgment of the avoidability.

One limitation of the study is that it is based on secondary analyses, although in fact outlined in the original study protocol. Further, although the clinical assessments were made in an assessor-blinded fashion, the filling up of the assessment scales was not blinded. On the other hand, the latter assessments did not differ markedly from the former ones, which points to a limited risk of bias. The study sample was mid-sized, and a larger number of patients would have strengthened the results. Further, an even broader approach regarding drug therapy could be valuable in future research. ${ }^{51-53}$ We were not able to specifically investigate the effects of possible drug interactions in this study population. Thus, we cannot exclude the possibility that such interactions could have been involved in a few of the reported rehospitalizations.

Powerful patient safety efforts to avoid ADRs might lead to underestimation of the potential benefits of evidence-based drug therapy. This might have negative consequences for the elderly patients, and for the health care system as well. There is a need for larger studies of frail elderly patients, including evaluating rehospitalizations, which take both the perspective of underuse of drugs and ADRs into account.

\section{Conclusion}

In this study, one out of four frail elderly patients discharged from hospital were rehospitalized within 1 month. Independent risk predictors for rehospitalization were heart failure and anemia. Although ADRs constituted an important cause of rehospitalizations, assessed underuse of evidence-based drug treatment might be an even more frequent cause. Moreover, potentially avoidable rehospitalizations were more frequently associated with underuse of evidence-based drug treatment than with ADRs, although this finding should be interpreted with caution, since the number of avoidable ADR readmissions was small in this study. Reasonable patient safety efforts made to avoid ADRs in frail elderly patients must be balanced and combined with evidence-based drug therapy which can benefit these patients. This implies a need for intensified educational efforts regarding drug therapy for frail elderly patients.

\section{Acknowledgments}

This study was funded by grants from the Healthcare Subcommittee, Region Västra Götaland; Department of Research and Development, NU Hospital Group and the Fyrbodal Research and Development Council, Region Västra Götaland, Sweden. We acknowledge Göran Östberg and Maria Johansson for valuable discussions regarding clinical judgments in the study.

\section{Disclosure}

Björn W Karlson is an employee of AstraZeneca. The other authors report no conflicts of interest in this work. 


\section{References}

1. Bergman H, Ferrucci L, Guralnik J, et al. Frailty: an emerging research and clinical paradigm. Issues and controversies. J Gerontol A Biol Sci Med Sci. 2007;62(7):731-737.

2. Chen X, Mao G, Leng SX. Frailty syndrome: an overview. Clin Interv Aging. 2014;9:433-441.

3. Fried LP, Tangen CM, Walston J, et al; Cardiovascular Health Study Collaborative Research Group. Frailty in older adults: evidence for a phenotype. J Gerontol A Biol Sci Med Sci. 2001;56(3):146-156.

4. Rockwood K, Song X, MacKnight C, et al. A global clinical measure of fitness and frailty in elderly people. CMAJ. 2005;173(5):489-495.

5. Buta BJ, Walston JD, Godino JG, et al. Frailty assessment instruments: systematic characterization of the uses and contexts of highly-cited instruments. Ageing Res Rev. 2016;26:53-61.

6. Woodard J, Gladman J, Conroy S. Frail older people at the interface. Age Ageing. 2010;39(S1):i36.

7. Edmans J, Bradshaw L, Franklin M, Gladman J, Conroy S. Specialist geriatric medical assessment for patients discharged from hospital acute assessment units: randomised controlled trial. BMJ. 2013;347:f5874.

8. Dharmarajan K, Hsieh AF, Lin Z, et al. Diagnoses and timing of 30-day readmissions after hospitalization for heart failure, acute myocardial infarction, or pneumonia. JAMA. 2013;309(4):355-363.

9. Brennan JJ, Chan TC, Killeen JP, Castillo EM. Inpatient readmissions and emergency department visits within 30 days of a hospital admission. West J Emerg Med. 2015;16(7):1025-1029.

10. Morandi A, Bellelli G, Vasilevskis EE, et al. Predictors of rehospitalization among elderly patients admitted to a rehabilitation hospital: the role of polypharmacy, functional status and length of stay. $J \mathrm{Am} \mathrm{Med}$ Dir Assoc. 2013;14(10):761-767.

11. Zanocchi M, Maero B, Martinelli E, et al. Early re-hospitalization of elderly people discharged from a geriatric ward. Aging Clin Exp Res. 2006;18(1):63-69.

12. Hubbard RE, O'Mahony MS, Woodhouse KW. Characterising frailty in the clinical setting: a comparison of different approaches. Age Ageing. 2009;38(1):115-119.

13. Mahmoudi S, Taghipour HR, Javadzadeh HR, Ghane MR, Goodarzi H, Kalantar Motamedi MH. Hospital readmission through the emergency department. Trauma Mon. 2016;21(2):e35139.

14. Fabbian F, Boccafogli A, De Giorgi A, et al. The crucial factor of hospital readmissions: a retrospective cohort study of patients evaluated in the emergency department and admitted to the department of medicine of a general hospital in Italy. Eur J Med Res. 2015;20(1):6.

15. Kansagara D, Englander H, Salanitro A, et al. Risk prediction models for hospital readmission: a systematic review. JAMA. 2011;306(15):1688-1698.

16. Alassaad A, Melhus H, Hammarlund-Udenaes M, Bertilsson M, Gillespie U, Sundström J. A tool for prediction of risk of rehospitalisation and mortality in the hospitalised elderly: secondary analysis of clinical trial data. BMJ Open. 2015;5(2):e007259.

17. Kripalani S, Theobald CN, Anctil B, Vasilevskis EE. Reducing hospital readmission: current strategies and future directions. Аnnu Rev Med. 2014;65:471-485.

18. Linertová R, García-Pérez L, Vázquez-Díaz JR, Lorenzo-Riera A, Sarría-Santamera A. Interventions to reduce hospital readmissions in the elderly: in-hospital or home care. A systematic review. J Eval Clin Pract. 2011;17(6):1167-1175.

19. World Health Organization. International Drug Monitoring: The Role of the Hospital. Geneva, Switzerland: World Health Organization; WHO Tech Rep Ser No. 425; 1966.

20. Naranjo CA, Busto U, Sellers EM, et al. A method for estimating the probability of adverse drug reactions. Clin Pharmacol Ther. 1981;30(2):239-245.

21. Belhekar MN, Taur SR, Munshi RP. A study of agreement between the Naranjo algorithm and WHO-UMC criteria for causality assessment of adverse drug reactions. Indian J Pharmacol. 2014;46(1):117-120.
22. Hallas J, Harvald B, Gram LF, et al. Drug related hospital admissions: the role of definitions and intensity of data collection, and the possibility of prevention. J Intern Med. 1990;228(2):83-90.

23. Parameswaran Nair N, Chalmers L, Peterson GM, Bereznicki BJ, Castelino RL, Bereznicki LR. Hospitalization in older patients due to adverse drug reactions - the need for a prediction tool. Clin Interv Aging. 2016;11:497-505.

24. Hamilton HJ, Gallagher PF, O'Mahony D. Inappropriate prescribing and adverse drug events in older people. BMC Geriatr. 2009;9:5.

25. Marcum ZA, Amuan ME, Hanlon JT, et al. Prevalence of unplanned hospitalizations caused by adverse drug reactions in older veterans. J Am Geriatr Soc. 2012;60(1):34-41.

26. Conforti A, Costantini D, Zanetti F, Moretti U, Grezzana M, Leone $\mathrm{R}$. Adverse drug reactions in older patients: an Italian observational prospective hospital study. Drug Healthc Patient Saf. 2012;4:75-80.

27. Chan SL, Ang X, Sani LL, et al. Prevalence and characteristics of adverse drug reactions at admission to hospital: a prospective observational study. Br J Clin Pharmacol. 2016;82(6):1636-1646.

28. Pedrós C, Formiga F, Corbella X, Arnau JM. Adverse drug reactions leading to urgent hospital admission in an elderly population: prevalence and main features. Eur J Clin Pharmacol. 2016;72(2):219-226.

29. Rydberg DM, Holm L, Engqvist I, et al. Adverse drug reactions in a tertiary care emergency medicine ward - prevalence, preventability and reporting. PLoS One. 2016;11(9):e0162948.

30. Chan M, Nicklason F, Vial JH. Adverse drug events as a cause of hospital admission in the elderly. Intern Med J. 2001;31(4):199-205.

31. Bénard-Laribière A, Miremont-Salamé G, Pérault-Pochat MC, Noize P, Haramburu F; EMIR Study Group on Behalf of the French Network of Pharmacovigilance Centres. Incidence of hospital admissions due to adverse drug reactions in France: the EMIR study. Fundam Clin Pharmacol. 2015;29(1):106-111.

32. Vazin A, Zamani Z, Hatam N. Frequency of medication errors in an emergency department of a large teaching hospital in southern Iran. Drug Healthc Patient Saf. 2014;6:179-184.

33. Pedrós C, Quintana B, Rebolledo M, Porta N, Vallano A, Arnau JM. Prevalence, risk factors and main features of adverse drug reactions leading to hospital admission. Eur J Clin Pharmacol. 2014;70(3): 361-367.

34. Mangoni AA. Predicting and detecting adverse drug reactions in old age: challenges and opportunities. Expert Opin Drug Metab Toxicol. 2012;8(5):527-530.

35. Davies EA, O'Mahony MS. Adverse drug reactions in special populations - the elderly. Br J Clin Pharmacol. 2015;80(4):796-807.

36. Budnitz DS, Pollock DA, Weidenbach KN, Mendelsohn AB, Schroeder TJ, Annest JL. National surveillance of emergency department visits for outpatient adverse drug events. JAMA. 2006;296(15):1858-1866.

37. Lavan AH, Gallagher P. Predicting risk of adverse drug reactions in older adults. Ther Adv Drug Saf. 2016;7(1):11-22.

38. Payne RA, Abel GA, Avery AJ, Mercer SW, Roland MO. Is polypharmacy always hazardous? A retrospective cohort analysis using linked electronic health records from primary and secondary care. Br J Clin Pharmacol. 2014;77(6):1073-1082.

39. Kalisch LM, Caughey GE, Barratt JD, et al. Prevalence of preventable medication-related hospitalizations in Australia: an opportunity to reduce harm. Int J Qual Health Care. 2012;24(3):239-249.

40. Pugh D, Pugh J, Mead GE. Attitudes of physicians regarding anticoagulation for atrial fibrillation: a systematic review. Age Ageing. 2011;40(6):675-683.

41. Foody JM. Reducing the risk of stroke in elderly patients with nonvalvular atrial fibrillation: a practical guide for clinicians. Clin Interv Aging. 2017;12:175-187.

42. Komajda M, Hanon O, Hochadel M, et al. Contemporary management of octogenarians hospitalized for heart failure in Europe: Euro Heart Failure Survey II. Eur Heart J. 2009;30(4):478-486.

43. Díez-Villanueva P, Alfonso F. Heart failure in the elderly. $J$ Geriatr Cardiol. 2016;13(2):115-117. 
44. Allegri N, Rossi F, Del Signore F, et al. Drug prescription appropriateness in the elderly: an Italian study. Clin Interv Aging. 2017;12:325-333.

45. Budnitz DS, Lovegrove MC, Shehab N, Richards CL. Emergency hospitalizations for adverse drug events in older Americans. $N$ Engl J Med. 2011;365(21):2002-2012.

46. Ekerstad N, Karlson BW, Dahlin-Ivanoff S, et al. Is the acute care of frail elderly patients in a comprehensive geriatric assessment unit superior to conventional acute medical care? Clin Interv Aging. 2017;12:1-9.

47. Eklund K, Wilhelmsson K, Landahl S, Ivanoff-Dahlin S. Screening for frailty among older emergency department visitors: validation of the new FRESH-screening instrument. BMC Emerg Med. 2016;16(1):27.

48. Sonn U, Hulter-Åsberg K. Assessment of activities of daily living in the elderly. Scand J Rehabil Med. 1991;23(4):193-202.

49. Charlson ME, Pompei P, Ales KL, MacKenzie CR. A new method of classifying prognostic comorbidity in longitudinal studies: development and validation. J Chronic Dis. 1987;40(5):373-383.
50. Rubenstein LZ, Harker JO, Salvà A, Guigoz Y, Vellas B. Screening for undernutrition in geriatric practice: developing the short-form mininutritional assessment (MNA-SF). J Gerontol A Biol Sci Med Sci. 2001;56(6):M366-M372.

51. Patient-Centered Primary Care Collaborative (PCPCC). The PatientCentered Medical Home: Integrating Comprehensive Medication Management to Optimize Patient Outcomes. Resource Guide. 2nd ed. Washington, DC: Patient-Centered Primary Care Collaborative; 2012.

52. Forster AJ, Murff HJ, Peterson JF, Gandhi TK, Bates DW. The incidence and severity of adverse events affecting patients after discharge from the hospital. Ann Intern Med. 2003;138(3):161-167.

53. Forster AJ, Murff HJ, Peterson JF, Gandhi TK, Bates DW. Adverse drug events occurring following hospital discharge. J Gen Intern Med. 2005;20(4):317-323. 


\section{Supplementary material}

Table SI Early rehospitalizations probably not due to ADRs or underuse of evidence-based drug treatment

\begin{tabular}{|c|c|c|c|c|c|}
\hline Case & $\begin{array}{l}\text { Primary diagnosis at index } \\
\text { discharge }\end{array}$ & $\begin{array}{l}\text { Main reported cause of } \\
\text { rehospitalization }\end{array}$ & $\begin{array}{l}\text { Primary diagnosis } \\
\text { at discharge from } \\
\text { rehospitalization }\end{array}$ & $\begin{array}{l}\text { Probably } \\
\text { avoidable } \\
\text { rehospitalization }\end{array}$ & $\begin{array}{l}\text { Death at } \\
\text { rehospitalization }\end{array}$ \\
\hline I & COPD with exacerbation & Dyspnea & COPD with exacerbation & No & No \\
\hline 2 & Stroke & Dyspnea & Bronchitis & No & No \\
\hline 3 & Septicemia & Dyspnea & Septicemia & No & No \\
\hline 4 & Septicemia & Wound & Orthopedic care & No & No \\
\hline 5 & Wound infection & Paresis & Cerebral infarction & No & Yes \\
\hline 6 & Septicemia & Tiredness & Endocarditis & No & No \\
\hline 7 & Pneumonia & Coughing & Pneumonia & No & No \\
\hline 8 & Atrial fibrillation & Nausea & Atrial fibrillation & No & No \\
\hline 9 & Myocardial infarction & Dyspnea & Heart failure & No & No \\
\hline 10 & Nausea & Swollen urogenital organ & Paraphimosis & No & No \\
\hline II & Atrial fibrillation & Dyspnea & Dyspnea & No & No \\
\hline 12 & Urinary tract infection & Worsened general condition & Urinary tract infection & No & No \\
\hline 13 & Urinary tract infection & Abdominal and back pain & Vertebral compression & No & No \\
\hline 14 & Urinary tract infection & Falling & Tibia fracture & No & No \\
\hline 15 & Heart failure & Dyspnea & Septicemia & No & Yes \\
\hline 16 & Pain & Foot pain & Foot distorsion & No & No \\
\hline 17 & Pneumonia & Fever & Pneumonia & No & No \\
\hline 18 & Anemia & Tiredness & Calici infection & No & No \\
\hline 19 & Nausea & Malnutrition & Hiatus hernia & No & No \\
\hline 20 & Pneumonia & Dyspnea & Pneumonia & No & No \\
\hline 21 & Heart failure & Chest pain & Cholecystitis & No & No \\
\hline 22 & Anemia & Fainting & Pulmonary edema & No & Yes \\
\hline 23 & Coughing & Headache & Blood pressure fall & No & No \\
\hline 24 & Myocardial infarction & Chest pain & Myocardial infarction & No & No \\
\hline 25 & Pulmonary hypertension & Heart failure & Heart failure & No & No \\
\hline 26 & Pneumonia & Coughing & Urinary tract infection & No & No \\
\hline 27 & Vertebral compression & Dysarthria & Cerebral infarction & No & No \\
\hline 28 & Anemia & Worsened general condition & Septicemia & No & No \\
\hline 29 & Septicemia & Tiredness & Urinary tract infection & No & No \\
\hline 30 & Urinary tract infection & Hip fracture & Hip fracture & No & No \\
\hline 31 & Endocarditis & Absence attack & Urinary tract infection & No & No \\
\hline 32 & Anemia & Tiredness & Anemia & No & No \\
\hline 33 & Heart failure & Tiredness & Heart failure & No & No \\
\hline 34 & Heart failure & Falling & Heart failure & No & Yes \\
\hline 35 & Headache & Atrial fibrillation & Atrial fibrillation & No & No \\
\hline 36 & Heart failure & Fever & Diverticulitis & No & No \\
\hline 37 & Pneumonia & Tiredness & Urinary bladder cancer & No & No \\
\hline 38 & Dermal infection & Suspected infection & Dermal infection & No & No \\
\hline 39 & Heart failure & Heart failure & ACE/ARB & Dyspnea & Heart failure \\
\hline 40 & Pulmonary embolism & Abdominal pain & Pleural effusion & No & No \\
\hline 41 & Vertigo & Worsened general condition & Vertigo & No & No \\
\hline 42 & COPD with exacerbation & Dyspnea & COPD with exacerbation & No & No \\
\hline 43 & Myocardial infarction & Paresis & Cerebral infarction & No & No \\
\hline 44 & Heart failure & Chest pain & Angina pectoris & No & No \\
\hline 45 & Erysipelas & Leg ulcers & Peripheral arterial insufficiency & No & No \\
\hline 46 & Vertigo & Vertigo & Vertigo & No & No \\
\hline 47 & Pneumonia & Coughing & Tiredness & No & No \\
\hline 48 & Pneumonia & Dyspnea & Pulmonary embolism & No & No \\
\hline 49 & Hip fracture & Abdominal pain & lleus & No & No \\
\hline 50 & COPD with exacerbation & Dyspnea & COPD with exacerbation & No & Yes \\
\hline 51 & Urinary tract infection & Fever & Urinary tract infection & No & Yes \\
\hline
\end{tabular}

(Continued) 
Table SI (Continued)

\begin{tabular}{|c|c|c|c|c|c|}
\hline Case & $\begin{array}{l}\text { Primary diagnosis at index } \\
\text { discharge }\end{array}$ & $\begin{array}{l}\text { Main reported cause of } \\
\text { rehospitalization }\end{array}$ & $\begin{array}{l}\text { Primary diagnosis } \\
\text { at discharge from } \\
\text { rehospitalization }\end{array}$ & $\begin{array}{l}\text { Probably } \\
\text { avoidable } \\
\text { rehospitalization }\end{array}$ & $\begin{array}{l}\text { Death at } \\
\text { rehospitalization }\end{array}$ \\
\hline 52 & Pneumonia & Hand pain & Pneumonia & No & No \\
\hline 53 & COPD, exacerbation & COPD, exacerbation & Antibiotics & Cough, dyspnea & $\begin{array}{l}\text { COPD, } \\
\text { exacerbation }\end{array}$ \\
\hline 54 & COPD with exacerbation & Dyspnea & Heart failure & No & No \\
\hline 55 & Pneumonia & Coughing & Pneumonia & No & Yes \\
\hline 56 & Heart failure & Worsened general condition & Pneumonia & No & No \\
\hline 57 & Cholecyctitis & Hip pain & Hip fracture & No & No \\
\hline 58 & Heart failure & Cardiac arrest & Cardiac arrest & No & Yes \\
\hline 59 & Atrial fibrillation & Chest pain & Chest pain & No & No \\
\hline 60 & Vertebral compression & Bleeding & Vertebral fracture & No & No \\
\hline 61 & Urinary tract infection & Fever & Utero-vaginal prolapsis & No & No \\
\hline 62 & Orthostatism & Falling & Encephalopatia & No & No \\
\hline 63 & Pleural effusion & Dyspnea & Dyspnea & No & No \\
\hline 64 & Chest pain & Chest pain & Angina pectoris & No & No \\
\hline
\end{tabular}

Abbreviations: ADR, adverse drug reaction; COPD, chronic obstructive pulmonary disease.

\section{Publish your work in this journal}

Drug, Healthcare and Patient Safety is an international, peer-reviewed open access journal exploring patient safety issues in the healthcare continuum from diagnostic and screening interventions through to treatment, drug therapy and surgery. The journal is characterized by the rapid reporting of reviews, original research, clinical, epidemiological and post-marketing surveillance studies, risk management, health literacy and educational programs across all areas of healthcare delivery. The manuscript management system is completely online and includes a very quick and fair peer-review system. Visit http://www.dovepress.com/ testimonials.php to read real quotes from published authors. 